\title{
Using Game Psychology in Information System Design for Sustainable Behavior Changes
}

\author{
Danny Oldenhave*, Theo van der Weide ${ }^{\dagger}$, Stijn Hoppenbrouwers ${ }^{\ddagger}$, Jos Sauren ${ }^{\S}$ \\ * Atos, The Netherlands, Radboud University, The Netherlands, Email: danny.oldenhave@ atos.net \\ $\dagger$ Radboud University, The Netherlands Email: tvdw@cs.ru.nl \\ $\ddagger$ HAN University of Applied Sciences, Radboud University, The Netherlands Email: stijn.hoppenbrouwers@ @an.nl \\ $\S$ Netherlands Tax and Customs Administration, The Netherlands Email: jmp.sauren@belastingdienst.nl
}

\begin{abstract}
Gamification as a topic is getting increasing attention within organizations as a method of organizing and structuring business processes. Gamification is about using game elements in a non-game context with the intention to effectuate a sustainable behavior change. In this paper we introduce Persuasive and Motivational Design (PMD) for information system design methods. This method applies Game Psychology as a safeguard to guarantee sustainable behavior changes that are required for a successful introduction of solutions designed with PMD. PMD has been used for over two years in a course program and has been tested in a business setting. The impact (such as the experiences during the validation of PMD in a case study) will be addressed in an upcoming paper.
\end{abstract}

\section{INTRODUCTION}

This paper aims to contribute to the design of information systems. Gamification has been recognized as a high potential approach [1] to build better cooperation models, also in a business context, especially when processes tend to be loosely structured and require creative and ad-hoc solutions. Gamification may help to build better cooperation models for such cases. As a consequence, the introduction of such models requires the actors (the cooperators of the business) to change their behavior. The sustainability of the behavior change is the most critical success factor for a successful introduction of a new way of working.

This paper reports on the second step in a line of research in which an industrial partner cooperates with academic partners. Ideas that originated in the practical context of the industrial partner are combined with theoretic models that have been developed in academia. In our paper we will discuss these models and their application, and also report about the experiences so far. In this approach we take the perspective that gamification can be used to support knowledge workers in their daily jobs and to facilitate them in a behavior change process. We define a conceptual framework using (game) psychological theory to make an information system design based on the use of game elements guided by these psychological theories.

Gamification is often defined as: "an informal umbrella term for the use of game elements in non-gaming systems to improve user experience and user engagement" [2]. Another form of the use of games within organizations is Serious
Games [3]. These are real games (e.g. management games) with a serious goal and not just entertainment. Serious Games are often used to create awareness or teach about some subject [4]. In this paper we focus on the use of gamification.

Games have a great influence on our current society and are often described as a "powerful force in nature" [5] and are "aligned with the current mindset of the current generation" [5]. Gamification is therefore getting increasing attention. Gartner describes gamification as a "significant trend in recent years" and "will have a significant impact in many domains, and in some fields, the use of game mechanics will have a transformational impact" [6]. Gamification currently has been introduced into fields of e.g. sustainability [7], education [8], [9], method engineering [10], collaboration [4], [11], knowledge management [12], employee engagement [13] and organizational design [14].

In their latest Hype Cycle, Gartner shows that Gamification is currently (2016) going through the 'Trough of Disillusionment'. They stated that " 80 percent of current gamified applications will fail to meet business objectives primarily due to poor design" [1], [6]. Although so many gamification applications have failed [1], there has been little research on how to make some new behavior more sustainable and the solution itself more successful (according to the authors at the moment of writing). Gamification is not just about 'just adding points' [5] or 'Points, Badges and Leaderboards' [15]. When not thought through properly, such solutions could lead to 'meaningless gamification' [16] or players could even feel exploited [17].

The layout of this paper is as follows. First, in Section II we discuss sustainable behavior change and how this may be obtained. In Section III we overview the relevant parts of Game Psychology. In Section IV we apply Game Psychology on information system design to obtain a sustainable behavior change. Then, in Section V we report about our experiences so far, consisting of a training that has been given for some years already, and an experiment conducted at the Netherlands Tax and Customs Administration. We close with some conclusions and suggest further research (Section VI). 


\section{Sustainable Behavior Change}

Changes regarding behavior are usually necessary when introducing a new (information) system within an organization. Employees need to work or even think differently than they are used to. The required behavior to support this new way of working and thinking should be triggered within the target audience. Most behavior change programs only focus on creating awareness, but this is "only one part of a behavior change program" [18]. For a behavior change to be sustainable, psychological knowledge can play a central role [19]. This knowledge should be used to not only create awareness, but also to continue and secure the new behavior making the change sustainable [20], [21].

A first step in a sustainable behavior change is for the target audience to be aware of the personas concerning their current behavior. Serious Games are often used to make people aware of their current behavior [2], [22]. Though this paper does not focus on Serious Games, the framework suggested could also be used to create a Serious Game solution.

To sustain the new behavior, gamification can be used [13], [23] because the target audience will be stimulated continuously. It is important to think about how the target audience should be triggered to start the new behavior. Based on the personas related to the current behavior of the target audience, we can identify the right kind of game elements which will have an effect on the target audience. After the target audience begins to show the target behavior it is important to secure and continue the behavior. The way the target audience is being triggered will change over time [24]. When the target audience is being motivated enough to show the target behavior, and is being triggered to show the actual behavior, sending only a reminder to them to show the behavior will be enough [24]. Continuing rewarding the target audience when they already are motivated can result in a lack of motivation, because "creativity and intrinsic interest diminish if a task is done for gain" [25]. It is therefore important to keep measuring the target audience and to conclude if a new trigger through a new set of game elements is needed.

\section{GAME PSYCHOLOGY}

It has been shown that gamification can be used to motivate people [8], [16], [26] and to facilitate a target audience into some behavior change [13], [23]. Gamification can be used to achieve such a behavior change by using psychological theories [19]. By understanding human behavior and what motivates people, we can also identify whether gamification is the right kind of tool to use. When people are already motivated and show the desired behavior in some way, gamification will not add anything and may even lead to the demotivation of the players [16], [25], [27].

Personality theory is an important issue in Psychology. Many approaches have been proposed, for an overview see for example [28] or [29]. A special approach to define a personality typology typically follows the following lines:

1) find personality criteria (traits) that are measurable;
2) choose a set of (more or less) independent criteria that match the characteristics for some application area;

3) for each criterion, determine two dominant scores, for example, a low and a high score;

This leads to a set of $2^{n}$ personality types, if $n$ is the number of criteria. This set of personality types is a framework for further reasoning in the chosen application area. An important representant of this approach is Big Five [30] in which five criteria are selected: openness to experience, conscientiousness, extraversion, agreeableness and neuroticism. It has been argued that these five factors are sufficient [31], [32]. Other popular approaches are Belbin [33] and Myers-Briggs [34]. A more extensive approach is the Occupational Personality Questionnaire (OPQ, [35]) that measures and interprets job competencies in organizations in which the criteria are presented as nested sets, thus allowing to make classifications for the personality types. OPQ was developed as a tools for human resource management, describing the personal requirements for some function in some business culture, and selecting people who are inherently of the required type(s) or close enough to call.

In this paper we focus at the Bartle player types, since this model has been developed especially for a gaming environment (such as a gamification solution). In the near future we intend to mix the business oriented approach and the gamification oriented approach into a method dedicated to using gamification in information system design.

Bartle first based his model on two dimensions [36]. Later he refined this model, adding a 3rd dimension, and called the new classification Bartle-8 [37]. Because of the popularity of this model, there are several variations on this. For a brief overview see [38]. In this paper we restrict ourselves to the Bartle- 4 model, which helps create a more balanced design of all types within a gamification solution when used correctly [36].

When creating a design for a gamification solution (we suggest the term persuasive and motivational design) the use of Game Psychology is required. In game psychology it is argued that the psychology behind games can shape and sustain a behavior change [13], [23], [39]. Game Psychology explains how people should interact with game elements using motivation and behavior theories from different fields of psychology. For an overview, see [40]. In this paper we suggest several psychological and design theories which can be used to conceptualize a gamification solution in a sustainable manner. The psychological theories are based on three important aspects of Game Psychology: Goals, Behavior and Motivation.

\section{A. Goals}

By using an Information System an employee should reach some business objectives (or goals) set by an organization or some personal related goal set by the employee. By implementing the right kind of game elements we can help the target audience (or players) reach these goals [8], [16], [41], [42]. The effort someone is willing to put into reaching the goals can 


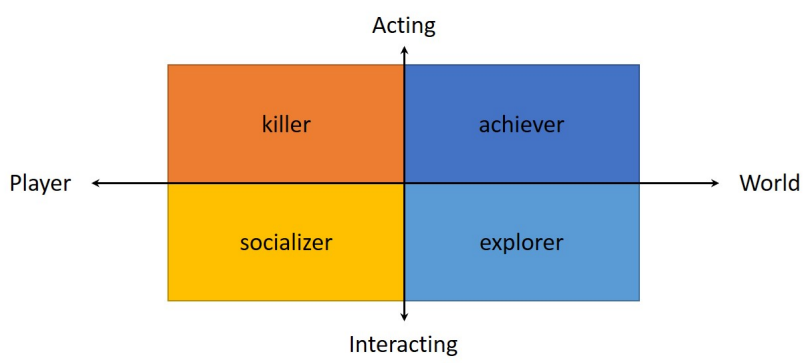

Fig. 1. Bartle Player Types [36]

be influenced by the difficulty of these goals. Slightly more difficult goals tend to increase performance by the players [43]. In a gamification context this also has been reported. Breaking down larger goals into sub-goals can also increase the effort by making the end goal seem more achievable and increasing the self-efficacy of the players [21], [43]. Setting goals and breaking them down into sub-goals can also be seen within games in the form of a level system. The final goal (e.g. defeating the final boss) is broken down into smaller goals (levels) with assignments based on the current level of the player.

\section{B. Behavior}

To change behavior of our players we must understand behavior and how we can formalize. Considering the background of the players, understanding their current behavior and which behavior is required to reach the business objectives of the information system. It is important to realize that this required behavior should benefit the players as well [16], [44]. When looking at a behavior change, we start off with some kind of awareness on why people should change and on how people are currently working. As stated before, this can be accomplished by using Serious Games. After awareness has been created, the new behavior should be secured and continued. This can be done by some form of operant conditioning by the use of reinforcers [20], [21], [45] which could result to internalization [27], [46]. When some new behavior is not being reinforced, people will fall back into their old behavior [20]. The securing and continuing of some new behavior is mostly forgotten and therefore often the reason why solutions have failed in the past.

To design for a sustainable behavior change it is important to formalize behavior. We suggest the use of the Bartle Player Types [36] to map and visualize certain behavior and the required distribution of each player type. Bartle distinguishes four kinds of 'player types' by plotting them on two dimensions. These dimensions are: 'Players vs the World' and 'Acting vs Interacting'. The player types are depicted in Figure 1.

The four player types are described as [36]:

1) Killers (acting on other players): Imposing upon others. The players use the game to cause distress to (or, in rare circumstances, to help) other players of the game.

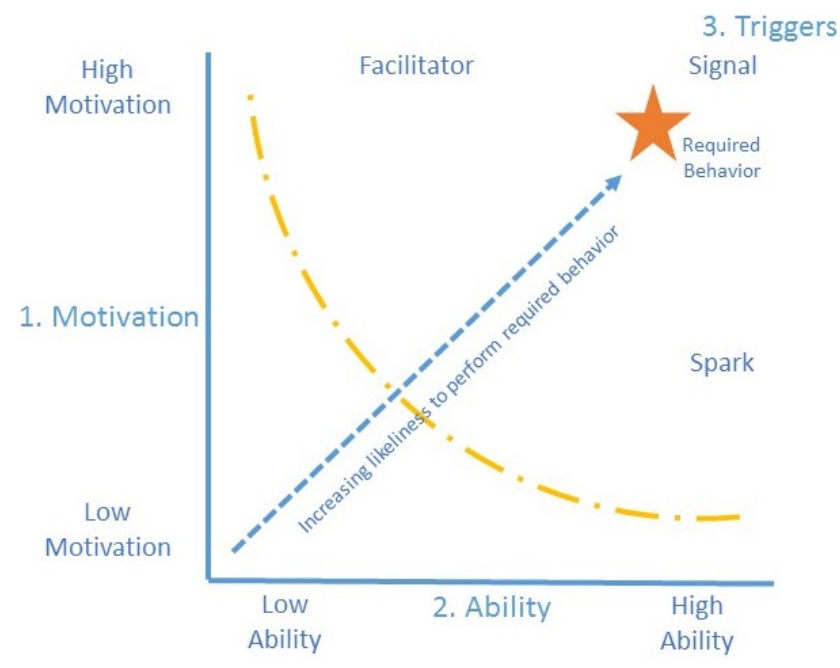

Fig. 2. Fogg Behavior model (FBM) [24]

2) Achievers (acting on the world): Achievements within the context of the game. Players give themselves goals within the game, and set out to achieve them.

3) Socializers (interacting with other players): Socialize with others. Players use the communicative facilities of the game as a context in which to interact with other players.

4) Explorers (interact with the world): Exploring the game. Players try to find out as much as they can about the game. Mapping its topology and experimentation with its physics.

\section{Motivation to change}

Getting employees more intrinsically motivated can have several benefits for an organization. When employees are more intrinsically motivated they deliver higher quality work, have a higher work satisfaction, have a lower absenteeism and show a lower turnover [20]. When talking about changing current behavior to required behavior by motivating the players, it is paramount to understand how behavior emerges. An intention towards a behavior is created when people are motivated and have the ability to show the requested behavior. To transfer this intention into actual behavior, a trigger is needed [20], [47]. To facilitate a behavior change, we suggest the use of the 'Fogg Behavior Model' (FBM) [24] which encompasses motivation, ability and triggers. The FBM is depicted in Figure 2.

The first element to change behavior, according to the Fogg Behavior Model, is motivation. When we look more closely at motivation, we can distinguish two kinds of motivation: extrinsic and intrinsic [20], [21], [27]. Extrinsic motivation is motivation because we are required to do something or we get a reward for it. Intrinsic motivation is motivation because we simply love doing something, think it is important and/or see some improvements in our life (e.g. self-development); no reward (or consequence or person) is required to motivate 
someone into showing a certain behavior. Psychologists Ryan $\&$ Deci [27] in their 'Organismic Integration Theory' distinguish four levels in extrinsic motivation which someone needs to go through to get intrinsically motivated. Ranging from highly extrinsic, passive behavior to more intrinsic behavior we have: External regulation (doing something because we must do it, sometimes getting punished if we will not do it), Introjection (doing something for status, self-esteem or social acceptance), Identification (doing something because we can identify with the meaning but still need some trigger) and Integration (doing something because it is related to own goals, no real need for a trigger but not yet fully intrinsic). The organismic integration theory, together with intrinsic motivation, can be used to identify where the target audience is located on the motivation axis of the FBM.

Next to motivation it is important for someone to be able to perform the requested behavior [20], [21] and that the target audience can get better in what they do (mastery; to increase the ability [26]). Fogg distinguishes in his model six types of ability, which a conceptual designer should consider when identifying where the target audience is located on the ability axis of the FBM. Those types of ability are: Time, Money, Physical effort, Brain cycles (mental ability, e.g. IQ), Social deviance and Non-routine.

It is necessary to have some trigger to effectuate the requested behavior in our players. It is not always possible to trigger an intention into the requested behavior [20], [47]. Fogg [24] describes in his article a 'behavior activation threshold': "When the combination of motivation and ability places a person above the behavior activation threshold, then a trigger will cause that person to perform the target behavior. If a person is underneath this threshold, then a trigger will not lead to the target behavior". Fogg described that this threshold could be illustrated as a curved line from the upper left corner to the bottom right in the FBM. See Figure 2. The FBM distinguishes three kinds of triggers to effectuate behavior, when the target audience is above the behavior activation threshold: Spark (focused on motivation, when ability is high), Facilitator (focuses on ability, when motivation is high) and Signal (a reminder, when ability and motivation are high).

When the players of the solution are triggered in the right way and their place in the Fogg Behavior Model reaches the area of the Signal trigger, the players are almost intrinsically motivated (Integration). To get the players to be intrinsically motivated and keep them there, we need to keep the elements for intrinsic motivation in place during the entire lifetime of the information system. According to Daniel Pink [48] there are three elements necessary to get someone to be intrinsically motivated and to keep them motivated (next to providing the Signal trigger):

1) Autonomy: freedom within some set boundaries

2) Purpose: showing the meaning of the required behavior 'meaningfulness'

3) Mastery: getting better at what you do

\section{Using Game Psychology in System Design}

To conceptualize a gamification solution during the design of an information system, we suggest a design framework using game psychology (as explained in the previous sections), adopted from a sound approach (the 'Gamification Design Framework') as described by Werbach \& Hunter [15]. We will refer to the resulting information system design method as Persuasive and Motivational Design (PMD).

The introduction of new technology or systems within organizations has lead in many situations to non-trivial changes within the organizations [20]. Mostly, the introduction of technology requires a new way of thinking and a new way of working. Consequently, some change in behavior will be required, not only for those who will be working with a new system, but possibly also for other cooperators. During the design of an Information System, it is important to think about the intended users in the context of this system. The intention of PMD is to facilitate a sustainable behavior change among the users to help them reach their objectives [8], [16], [41].

The information system design method that we propose uses the steps that have been introduced in the framework from Werbach and Hunter [15], extended with a (last) seventh step that is concerned with testing (validating) the design so far. We also add a control structure to these steps, allowing for an iterative approach based on agile principles. The results of the final seventh step will be used as input for the first step, allowing for an iterative approach to use PMD to design for a sustainable behavior change during the design of an information system. This framework therefore also ties in with popular agile approaches such as Scrum or DevOps. Next we suggest how a designer can achieve the end result of each step by using Game Psychology. Because we want to design for sustainable behavior change, the most important actor (processor) is the target audience. Using several game psychological theories and design theories, we can determine what requirements are needed for this processor to show the requested behavior and if the processor is able to show the required behavior at all.

The design framework, as we suggest it, is displayed in Figure 3. Roughly the framework consists of 4 layers. The top layer starts with the definition of a conceptual language for the rest of the design process. Then in the next layer the intended and initial situation are described in terms of this conceptual language, after which the construction steps are performed. Level 3 defines a new psychological target, that subsequently is analyzed and realized by selected game elements. Level 4 is a testing layer after which the design process may stop or make a new iteration starting form level 3 . Where the first step of the framework helps designers define the purpose of the solution, the next four steps help create a foundation using PMD for the final solution to select the right game elements (step six) to relate to the purpose of the solution.

The individual steps are:

1) Problem and Objectives: What is the problem we want to solve, or the objective we would like to reach using 


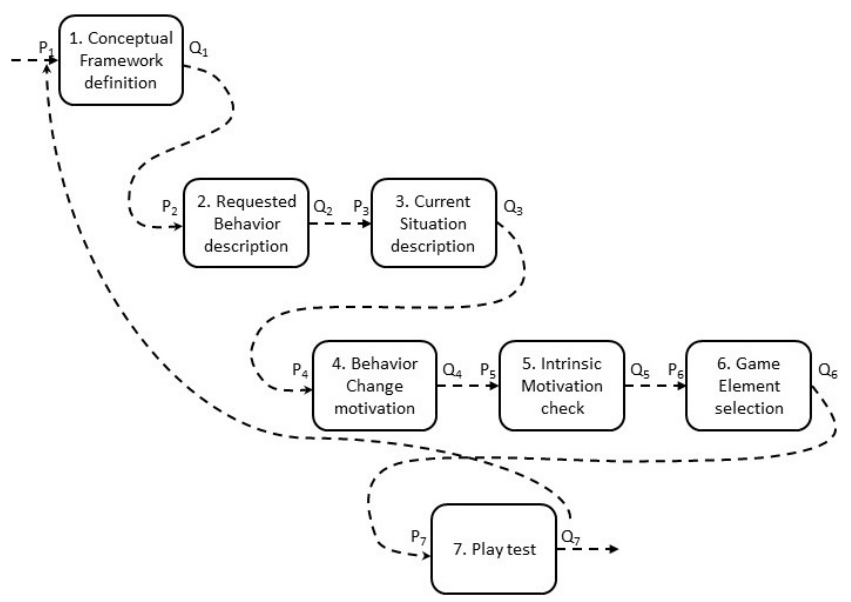

Fig. 3. The design framework

the gamification solution, the purpose of the solution

2) Requested Behavior: What behavior do we want the players to show, to reach the business objectives

3) Current Behavior: What are the characteristics of our players

4) Changing Current Behavior to Requested Behavior: How do we motivate the players to change their current behavior into the required behavior. Can the target audience perform the required behavior?

5) Fun: Make it fun for the players so they will be motivated

6) Game Elements: Select the right kind of game elements to relate to the purpose of the solution

7) Playtest: Test if the solution triggers your target audience in the right kind of way to show the requested behavior by playing and testing an iteration of the solution

The results of the playtest at the end of the approach will be input for a next iteration of going through the framework. This is not only during designing and creating the actual solution, but also when the solution has been implemented within an organization.

After the Information System had been designed and the framework has been used to include some persuasive and motivational design for a sustainable behavior change, it can be implemented within an organization. To keep a behavior change sustainable, $\mathrm{KPI}^{1}$ monitoring and mechanisms (game elements) tuning will remain important even after implementation, because people change over time [20], [21].

In the next sub-sections we describe each step in more detail and what the pre-conditions and post-conditions for each step are.

\section{A. Problems and Objectives}

The first step in the framework is to define the (business) objectives or goals for a gamification solution by setting up a conceptual framework definition. Games and gamification

${ }^{1}$ Key Performance Indicators can make it possible to achieve these goals in an engaging manner [2], [15], [16], [41]. What objectives, or goals, do we ultimately want to reach? An important question to think about is why we haven't reached these business objectives already. It is necessary to focus on the underlying problem, to increase the probability of reaching the business objectives. We suggest the use of a conceptual model to conclude which underlying problem is causing the business objectives not to be met yet [49].

Using a conceptual model, we can break down the business objectives (or research topic) into (in)dependent variables, which can be investigated: are they the root cause? [49]. This way we can give the correct scope to the final gamification solution. By addressing a real problem, some kind of 'meaningfulness' is for the players [5], [8], [41] which ultimately helps motivate them, by showing why the requested behavior is relevant "what's in it for me".

For this step we have:

Pre-condition $P_{1}$ : A situation has occurred (within an organization) which requires some change (e.g. the implementation of a new system or new way of working), also: test results of the playtest (Step 7), if an iteration is completed and the design does not yet meet the requirements.

Post-condition $Q_{1}$ : A conceptual model consisting of 1) the global goal, 2) a list of objectives, 3) variables needed to reach the business objective; to show which underlying problem is causing that the business objectives are not already met yet.

\section{B. Requested Behavior}

To reach the global goal of the gamification solution in an Information System, and therefore the defined business objectives, the conceptual model should be extended with the requested behavior decription and therefore a psychological approach is needed. So the next step in the framework is to delineate the requested behavior which will help reach our business objectives, i.e. what do we want the players to do?

The game psychological theory we use in this step, is the use of the Bartle Player Types [36] as explained in the previous section, to map the requested behavior. People cannot be labeled just as one player type, because behavior is linked to situations [21] and more than one player type can apply to that situation, but mostly one player type is dominant. The situation here is defined as the global goal in our conceptual model and our business objectives in the first step of the framework. By delineating the requested behavior and putting this as a variable in the conceptual model, we could derive from the player types and their actions (the requested behavior) that the global goal can be reached.

To formalize this behavior using the Bartle Player types we suggest the use of vectors. We register the number of characteristics for each Bartle player type (BPT) concerning the requested behavior $(p)$ and the degree (between 0 and 1) in which the various BPT can be associated with the requested behavior $(r)$. We can see this characterization as a vector in a four dimensional BPT-space, where the vector components indicate the degree of each BPT-dimension. The vector $\mathbf{r}$ is 
referred to as the role vector and the vector $\mathbf{p}$ as the player vector. The similarity $\operatorname{Sim}(\boldsymbol{p}, \boldsymbol{r})$ between the players vector $\mathbf{p}$ of the requested behavior and the association with it $\mathbf{r}$, can be obtained by taking the inner vector product:

$$
\operatorname{Sim}(p, r)=p \cdot r
$$

The similarity between two groups of players may be determined as the similarity of the centroid of both groups. The centroid of a group of players can be seen as a BPTvector containing the average characterization of a member of that group. This way it is possible to create a model of a certain behavior and can be visualized in a BPT model. By taking the similarity between the players vector and the role vector we can formalize the distribution of the player types within an organization to reach the global goal. For example, when the BPT-vector will be $(1621)^{T}$ as in (KillersAchieversSocializersExplorers $)^{T}$, we will need a distribution within the target audience where $10 \%$ of the players are Killers, 60\% are Achievers, 20\% are Socializers and $10 \%$ are Explorers.

For this step we have:

Pre-condition $P_{2}$ : Objectives of the solution (Step 1).

Post-condition $Q_{2}$ : Formal requested behavior which is needed to reach the general goal of the solution.

\section{Current Behavior}

The next step in de framework is to describe the target audience with a current situation decription, i.e. the players of the gamification solution. These players are the people who need to show the requested behavior. So the conceptual model can be exteded with the players and their current behavior. Everyone is different and everybody wants different things, so it is important to know who you are dealing with [20], [21]. A gamification solution will therefore only be meaningful and will most likely only work as intended, when the gamification solution is designed around the players and based on knowledge of the players' backgrounds [15], [16], [44].

To describe and formalize the current behavior of the players and current distribution of player type characteristics within the target audience, we again suggest the use of the Bartle player types and corresponding vectors as described in the previous step to list and depict the behavior which belongs to the current behavior of the players. Where the vector $\mathbf{p}$ will be the players vector concerning the current behavior and the vector $\mathbf{r}$ will be the role vector in which the various $B P T$ can be associated with the current behavior. The player vector can be obtained by interviewing a selection of the target audience and conducting a survey among the entire target audience. These two methods are well suited within the field of work psychology [21]. The role vector can be obtained by conducting observations to what extend the current behavior is being shown for each BPT.

For this step we have:

Pre-condition $P_{3}$ : None.
Post-condition $Q_{3}$ : Formal current behavior of the players of the solution.

\section{Changing Current Behavior to Requested Behavior}

The next step in the framework, after formalizing the required and current behavior of the players, is to think about how and if we can motivate the players to perform the requested behavior and to facilitate them in a behavior change when needed with some behavior change motivation. When requested and current behavior are (quite) similar, there still can be the need for some change when there is a lack of motivation. To enable some sort of (new) behavior, the target audience needs to be triggered in the right kind of way [24].

To conclude if the players can be triggered at all, and if so which trigger should be used, we suggest the use of the game psychological theory of the Fogg Behavior Model [24] as explained in the previous section. To map the players on the motivation axis of the Fogg Behavior Model, we suggest the use of the game psychological theory of the Organismic Integration Theory [27] as explained in the previous section as a scale on this axis. The players ability can be obtained by conducting observations of the players in their current environment based on the types of ability defined in the previous section. When requested and current behavior are (quite) similar, the ability is often very high. After mapping the players on the Fogg Behavior model, we can conclude whether the players can perform the required behavior (as formalized in the second step of this framework) and if so, which trigger should be used.

This step is also a check if gamification can be used to change the behavior of the players when needed. If the players are below the behavior activation threshold, we can conclude that gamification cannnot work in this situation. To keep the gamification solution and the behavior change sustainable when the players can be triggered, it is important to realize that the location on the FBM will change over time, and therefore the trigger could change. If the target audience is not properly triggered, this could lead to demotivation [16], [25], [27] and eventually the target audience could fall back under the behavior activation threshold. It is therefore important to measure several effects on the solution and the players to identify how they should be triggered over time.

For this step we have:

Pre-condition $P_{4}$ : Requested behavior of the players (Step 2) and current behavior of the players (Step 3).

Post-condition $Q_{4}$ : Indication to what extend the players are motivated and have the ability to show the target behavior. If the players are able to perform the requested behavior, and (if they can be triggered into showing the requested behavior) what trigger is needed to get them to show the requested behavior.

\section{E. Fun}

The next step in the framework is to induce fun and perform an intrinsic motivation check. How can we make something fun, so the players will be motivated to show 
the required behavior and therefore reach the general goal of the gamification solution? Fun is an important aspect in gamification [2], [16], [44]. To understand how to keep an activity fun and interesting, it is important to know how people see a task [8], [51].

To help the players see their tasks as fun, we suggest the use of a design theory called 'keys to fun' by Nicole Lazzaro [52]. She distinguishes four keys to fun:

- Hard fun: Emotions from Meaningful Challenges, Strategies, and Puzzles

- Easy fun: Grab Attention with Ambiguity, Incompleteness, and Detail

- Serious fun: Generate Emotion with Perception, Thought, Behavior, and Other People, getting better at something that matters

- People fun: Create Opportunities for Player Competition, Cooperation, Performance, and Spectacle. Fun out of playing with others.

Based on the requested and actual behavior of the target audience, one or more keys could be selected to engage the players into the required behavior. Like the used triggers, the kind of fun could change over time and effect measurements are necessary to keep the gamification solution sustainable. To get the players to be more engaged and induce another aspect of fun, we suggest the use of the design theory (and also a well known psychological theory) of Flow. Flow is described by Csikszentmihalyi [53] as "effortless action many people feel in moments that stand out as the best in their lives" or that people describe as "being in the zone". Csikszentmihalyi states that "it is the full involvement of flow, rather than happiness, that makes for excellence in life". Flow can emerge when skills and challenges are perfectly balanced. When challenges are too high, this can lead to frustration, and when someone's skills are too high, this can lead to boredom. The use of flow will help increase the ability of the players to perform the requested behavior (mastery), which helps get the players intrinsically motivated [48].

For this step we have:

Pre-condition $P_{5}$ : General goal of the gamification solution (Step 1), requested behavior of the players (Step 2), current behavior of the players (Step 3) and how the target audience should be triggered into showing the requested behavior (Step 4).

Post-condition $Q_{5}$ : What types of fun can be used to trigger the players; now and in the future (to keep it sustainable).

\section{F. Game Elements}

The first five steps will help a designer to create a persuasive motivational design of the solution during the design of an Information System. Based on this design the actual gamification solution (and therefore the sustainable behavior change) can be shaped by performing a game element selection of applicable game elements which relate to the purpose of the solution. These game elements will help trigger the players into the required behavior, based on their current characteristics, and will use some form of fun, thereby the concept of flow.
To select the game elements, we suggest the use of the pyramid of elements, as described by Werbach \& Hunter [15]. They distinguish three levels of game elements: Dynamics (high level conceptual elements; e.g. rules, constraints, emotions), Mechanics (verbs, to move the action forward; e.g. challenges, chance, cooperation/competition, feedback) \& Components (elements from games; e.g. achievements, badges, content unlocking, quests). The dynamics are on the top of the pyramid, so there are not many of them. The mechanics are in the middle of the pyramid, and there are a few more of them. The components are at the bottom of the pyramid, so there are many of them. All are related.

Another framework which is often used is the MDAframework by LeBlanc, Hunicke \& Zubek [50]. MDA stands for: Mechanics ("particular components of the game, at the level of data representation and algorithms"), Dynamics ("runtime behavior of the mechanics acting on player inputs and each other" and Aesthetics ("desirable emotional responses evoked in the player"). Van Bree, Copier \& Gaanderse [22] suggest in their 'second-order game design' that aesthetics cannot directly be designed, but are a result of: rules, engagement of players, evaluation of the design \& play testing. We therefore suggest the use of the pyramid of elements, which shows that aesthetics are a direct result of the correct implementation of elements on all three layers [15].

To select the game elements for the gamification solution, a conceptual designer should focus on the elements most strongly related to the current behavior of the players [8], [54] and the distribution of the player types within an organization. These elements should reward the effort of showing the requested behavior [8], [16] and the requested distribution of player types within the organization to reach the objectives of the solution. The selected game elements will work as a reinforcer when applied as soon as the players show the requested behavior [20]. This concept is based on Expectancy theory as described by Vroom [55]. All four player types, as identified by Bartle, have a set of game elements which will be relevant for them, e.g.: Killers are prone to battles and competition (Leaderboards), Achievers are prone to getting better in a game and be rewarded for that (Achievements), Socializers are prone to the social aspects of a game (chats) and Explorers are prone to investigating new things (interesting world to explore). By selecting those game elements which most affect the target audience and use them to reward them for showing the target behavior one can continue the behavior change.

After the game elements are selected, a designer will be able to create a functional design based on the information gathered in the current (and possibly previous) iterations. When a functional design has been created, a prototype (or an increment) of the solution can be build.

For this step we have:

Pre-condition $P_{6}$ : Requested behavior of the players (Step 2), current behavior of the players (Step 3), triggers (Step 4) and the types of fun (Step 5).

Post-condition $Q_{6}$ : Game elements (at all levels) to design for 


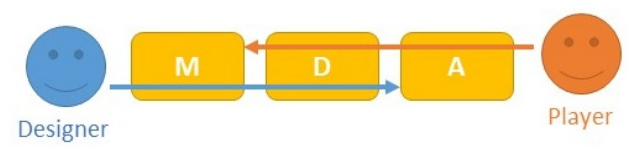

Fig. 4. Different views according to MDA-Framework [50]

a sustainable behavior change using gamification, a functional design and a possible prototype/increment of the gamification solution.

\section{G. Playtest}

When a first prototype has been created, it should be tested during a play test to check if the solution will help the players show the requested behavior and is correctly tied to the audience [22], [26], [56]. Le Blanc et al. [50] describe the necessity of play testing, because a designer and a player look at a game (or gamification solution) from different perspectives.

During a playtest a selection of the players will 'play' the gamification solution and test the persuasive and motivational design. A conceptual designer can see if the intended behavior and the right distribution of the player types is indeed shown, and can adapt the game when necessary based on the conclusions of the play test. By mapping the behavior of the players during the playtest by using the Bartle player types and corresponding vectors (as suggested in step 2 and 3 of the framework), the behavior can be compared to the vector of the requested behavior (step 2) of the solution. The design framework we suggest works as an iterative approach to conceptualize and design for a gamification solution. Based on the results of the playtest, a conceptual designer should start looking again at the scope of the gamification solution, as created during the first step of the framework and refine the solution by going through all the other steps again. When the gamification solution has been refined, it can be play tested again by a representative group selected from the target audience.

For this step we have:

Pre-condition $P_{7}$ : Prototype/increment of the gamification solution (Step 6).

Post-condition $Q_{7}$ : Test results of the playtest.

\section{USING AND EVALUATING THE FRAMEWORK}

After refining the framework, using the game psychology theories and the introduction of persuasive and motivational design for our information system design method, we started using and evaluating the framework. Over the past several years two courses regarding gamification, persuasive and motivational design and the framework have been taught and the method has been tested in a business setting.

\section{A. Course Program}

At Atos, a leader in digital services with a focus on business technology with circa 100,000 employees, the concept of persuasive and motivational design is being taught in the
Netherlands. Over two years, with eight different groups, over 50 students (internal Atos and external clients of Atos) have been educated in persuasive and motivational design at the moment of writing. In two courses (Foundation and Advanced - each five evenings) students learn about gamification, game psychology, persuasive and motivational design and sustainable behavior changes within organizations. At the end of each course the students are being tested by an exam and after successfully passing the exam (with a score over $75 \%$ correct) they receive their certificate. Only students who have received their certificate for the Foundation course are admitted to the Advanced course. The framework is central in both courses and each evening covers one or two steps of it. Applicable design theories and game psychological theories for those steps are being taught by plenary teaching, playing games and applying the theory to a case. Most students of the course program where following the courses to apply persuasive and motivational design in their own projects. The course is still being taught at Atos for their employees and interested externals.

A shorter version of the course program is also being taught in the form of a successful workshop with several clients of Atos. During the workshop we teach a group of people about persuasive and motivational design and where (not) to use it. Together with the participants we select a real and current business problem or business objective which is to be used during the workshop. Then we introduce the steps of the framework and give a brief introduction into the theories needed for those steps. At each step the participants will work in small groups (or as we call them: guilds) working on their own design to solve the problem and motivating the players to reach the set objectives. After all steps are thought off, a winner is selected by presenting their results and voting. A business case and project plan is then being created by Atos.

\section{B. A Case}

In addition to being taught in a course program and a workshop, the framework and the use of persuasive and motivational design has also been tested in a real business setting. The impact of this will be addressed in an upcoming paper, but we will give an overview of this business setting.

The case was done at the Netherlands Tax and Customs Administration (NTCA), where a Social Enterprise Platform (SEP) was introduced to support online collaboration among different divisions. The main research question was to what extend gamification could be implemented to support their employees into reaching their personal work-related goals more efficiently by using the SEP. The research has been done at one division of the NTCA. During this case we introduced the framework and game psychological theories we discussed in this paper. By following the steps of the framework (creating a conceptual model, delineating the required and current behavior, identifying the right motivational techniques and game elements) and applying the applicable game psychological theories, we created a design for a gamification solution, 
showing how PMD can be used to design for a sustainable behavior change within the NTCA.

\section{CONClusion AND Future RESEARCH}

We can conclude that with the use of the right game elements and motivation, underpinned by application of a dedicated framework for persuasive and motivational design, we can deliberately and purposefully design for sustainable behavior change using gamification during the design of an information system. However, this is only the case if the objective of the solution, the required behavior and target audience are well known. Furthermore, effect measurements (KPI monitoring) are necessary to evaluate if the solution remains sustainable within the organization and should possibly be adjusted through tuning mechanisms such as triggers and game elements, to remain tied to the target audience. We believe this framework could work with other kinds of applications as well, such as Virtual Reality.

We started by introducing the concept of persuasive and motivational design using several game psychology theories. The Bartle Player Types were used to shape the specific personas needed to describe the current behavior of the target audience and the target behavior we want the target audience to show in order to reach our business objectives. This way one can conclude if a change in behavior is necessary within the organization. After the need for change is identified, we suggest the use of the Fogg Behavior Model to conclude if the target audience can be facilitated into a behavior change. When this is the case, we suggest how the target audience can be triggered into the required behavior and how to get and keep it intrinsically motivated. Game elements to support this sustainable behavior change can then be selected by identifying which elements fit the target audience to reward them when showing the required behavior. The final step is to playtest the design with a representative selection of the target audience to play the solution and conclude if the target audience is showing the required behavior. The results of this playtest are used as input for a new iteration of the suggested framework to refine the design.

Future research will take the perspective of the rational use of gamification and persuasive motivational design to influence behavioral changes within organizations using 'human centered design'. A next step is to focus on how we can direct and influence behavior change within organizations and in particular on the individuals within the organization within some structure (organizationally). Finally we want to focus on the way of modeling by including the formalization of the models described in this paper, the way of controlling (by some correctness proof) and how we can validate if the concept of persuasive and motivational design does work (e.g. by cases, results, expert feedback and a measurable hypothesis).

\section{REFERENCES}

[1] E. N. Webb, "Gamification: When it works, when it doesnt," in Design, User Experience, and Usability. Health, Learning, Playing, Cultural, and Cross-Cultural User Experience. Springer, 2013, pp. 608-614.
[2] S. Deterding, D. Dixon, R. Khaled, and L. Nacke, "From game design elements to gamefulness: Defining 'gamification',' in Proceedings of the 15th International Academic MindTrek Conference, 2011.

[3] H. Kelly, K. Howell, E. Glinert, L. Holding, C. Swain, A. Burrowbridge, and M. Roper, "How to build serious games," Communications of the $A C M$, vol. 50, no. 7, pp. 44-49, 2007.

[4] D. Oldenhave, S. Hoppenbrouwers, T. van der Weide, and R. Lagarde, "Gamification to support the run time planning process in adaptive case management," in Lecture Notes in Business Information Processing, ser. Enterprise, Business-Process and Information Systems Modeling, vol. 147, 2013, pp. 385-394.

[5] J. van Bree and S. de Lat, "Complex systems and emergent behavior: Engaging with computer games to enrich organization studies," in Nyenrode Research Paper, ser. 11, no. 05. Nyenrode, November 2011, iSSN 1872-3934.

[6] Gartner, "Gartner says by 2014, 80 percent of current gamified applications will fail to meet business objectives primarily due to poor design," Web article, November 2012, Retrieved April 2016, from https://www.gartner.com/newsroom/id/2251015.

[7] R. Research, "Gaming for good," in Whitepaper. ROI Research Inc., 2011.

[8] J. McGonigal, Realitiy is Broken. Penguin Books, 2011.

[9] J. Simoes, R. D. Redondo, and A. F. Vilas, "A social gamification framework for a k-6 learning platform," Computers in Human Behavior, vol. 29, no. 2, pp. 345 - 353, 03 2013, iSSN 0747-5632.

[10] S. Hoppenbrouwers, P. V. Bommel, and A. Järvinen, "Method engineering as game design: an emerging hci perspective on methods and case tools," in Proceedings of the 13th International Workshop on Exploring Modeling Methods for Systems Analysis and Design (EMMSAD 2008), T. Halpin, H. E. Proper, and J. Krogstie, Eds. CEUR, 2008.

[11] S. Hoppenbrouwers and E. Rouwette, "A dialogue game for analysing group model building: framing collaborative modelling and its facilitation," Int. J. Organisational Design and Engineering, vol. 2, no. 1, pp. 19-40, 2012.

[12] C. Leeson, "Driving km behaviors and adoption through gamification," $K M$ World, vol. 22, no. 4, pp. 10-20, Apr 2013, color Photograph.

[13] M. Mehta and A. Kass, "Scores, badges, leaderboards, and beyond: Gamification and sustainable behavior change," in Whitepaper. Accenture, April 2012.

[14] J. van Bree, "Exploring the rules by playing the game," Ph.D. dissertation, Nyenrode Business Universiteit, 2013.

[15] K. Werbach and D. Hunter, For the Win: How Game Thinking Can Revolutionize Your Business. Wharton Digital Press, October 2012.

[16] S. Nicholson, "A user-centered theoretical framework for meaningful gamification," in Games+ Learning + Society, vol. 8, 2012.

[17] I. Bogost, "Persuasive games: Exploitationware," Web Article, May 2011, gamasutra.

[18] R. J. Sternberg and J. F. Wilson, Psychology. Thomson/Wadsworth, 2004.

[19] D. McKenzie-Mohr, "Fostering sustainable behavior through community-based social marketing." American psychologist, vol. 55, no. 5, p. 531, 2000.

[20] G. Alblas and E. Wijsman, Gedrag in organisaties, 3rd ed. Wolters Noordhoff, 2001.

[21] J. Arnold, Work Psychology: Understanding Human Behaviour in the Workplace, 4th ed. Prentice Hall - Financial Times, 2005.

[22] J. van Bree, M. Copier, and T. Gaanderse, "Designing an organisational rule set: experiences of using second-order organisational design in healthcare," Int. J. of Organisational Design and Engineering, vol. 1, no. $1 / 2$, pp. $29-54,2010$.

[23] C. Swan, "Gamification: A new way to shape behavior," Communication World, vol. 29, no. 3, pp. 13-14, May/Jun 2012.

[24] B. J. Fogg, "A behavior model for persuasive design," in Proceedings of the 4th international Conference on Persuasive Technology. ACM, 2009 , p. 40.

[25] A. Kohn, "Studies find reward often no motivator: Creativity and intrinsic interest diminish if task is done for gain," in Boston Globe, January 1987.

[26] G. Zichermann and C. Cunningham, Gamification by Design: Implementing Game Mechanics in Web and Mobile Apps. O'Reilly, 2011.

[27] R. M. Ryan and E. L. Deci, "Intrinsic and extrinsic motivations: Classic definitions and new directions," Contemporary Educational Psychology, vol. 25, p. 5467, 2000, university of Rochester. 
[28] S. K. Ciccarelli and J. N. White, Psychology: an exploration. Pearson, 2013.

[29] D. Keirsey, Please understand me 2. Prometheus Nemesis Book Company, 1998.

[30] S. D. Gosling, P. J. Rentfrow, and W. B. Swann, "A very brief measure of the big-five personality domains," Journal of Research in personality, vol. 37, no. 6, pp. 504-528, 2003.

[31] R. R. McCrae and P. T. Costa, "Validation of the five-factor model of personality across instruments and observers." Journal of personality and social psychology, vol. 52, no. 1, p. 81, 1987.

[32] P. T. Costa and R. R. McCrae, "Four ways five factors are basic," Personality and individual differences, vol. 13, no. 6, pp. 653-665, 1992.

[33] R. M. Belbin, Team roles at work. Routledge, 2012.

[34] I. B. Myers, M. H. McCaulley, and A. L. Hammer, Introduction to Type: A description of the theory and applications of the Myers-Briggs type indicator. Consulting Psychologists Press, 1990.

[35] P. Saville, G. Sik, G. Nyfield, J. Hackston, and R. Maclver, "A demonstration of the validity of the occupational personality questionnaire (opq) in the measurement of job competencies across time and in separate organisations," Applied Psychology, vol. 45, no. 3, pp. 243262, 1996.

[36] R. Bartle, "Hearts, clubs, diamonds, spades: Players who suit muds," Journal of MUD research, vol. 1, no. 1, p. 19, 1996.

[37] R. A. Bartle, Designing virtual worlds. New Riders, 2004.

[38] B. Stewart, "Personality and play styles: A unified model," Gamasutra September, vol. 1, 2011.

[39] I. Blohm and J. M. Leimeister, "Gamification: Design of it-based enhancing services for motivational support and behavioral change," Business \& Information Systems Engineering, vol. 5, no. 4, pp. 275 - 278, 08 2013, iSSN 1867-0202.

[40] I. R. M. Association et al., Gamification: Concepts, Methodologies, Tools, and Applications. IGI Global, 2015.

[41] G. Costikyan, "I have no words \& i must design: Toward a critical vocabulary for games," in Proceedings of Computer Games and Digital Cultures Conference, F. Mäyrä, Ed. Tampere: Tampere University Press, 2002, pp. 9-33.

[42] S. Nicholson, "A recipe for meaningful gamification," in Gamification in education and business. Springer, 2015, pp. 1-20.

[43] E. A. Locke, "Toward a theory of task motivation and incentives," Organizational Behavior and Human Performance, vol. 3, no. 2, pp. 157 - 189, 1968. [Online]. Available: http://www.sciencedirect.com/science/article/pii/0030507368900044

[44] J. Schell, The Art of Game Design: A Book of Lenses. Taylor \& Francis Inc, 2010.

[45] B. Skinner, "The operational analysis of psychological terms," Psychological Review, vol. 52, pp. 270-277, 1945.

[46] R. M. Ryan, C. S. Rigby, and A. Przybylski, "The motivational pull of video games: A self-determination theory approach," Motivation and Emotion, vol. 30, no. 4, pp. 344-360, December 2006.

[47] H. D. Vries and E. Backbier, "Self-efficacy as an important determinant of quitting among pregnant women who smoke: the o-pattern," Preventive Medicine, vol. 23, p. 167174, 1994.

[48] D. H. Pink, Drive: The Surprising Truth About What Motivates Us. Riverhead Books, 2011.

[49] J. Segers, Methoden voor de maatschappijwetenschappen. Van Gorcum, 2002.

[50] M. LeBlanc, R. Hunicke, and R. Zubek, "Mda: A formal approach to game design and game research," in Proceedings of the Challenges in Game AI Workshop. San Jose: Game Developers Conference, 2004.

[51] D. Brown, Tricks of the Mind. Channel 4 Books, 2007.

[52] N. Lazzaro, "Why we play games: Four keys to emotion without story," in Whitepaper. XEODesign, March 2004.

[53] M. Csikszentmihalyi, "Finding flow," Psychology Today, July/August 1997.

[54] D. Kirkpatrick, "B2b social media: Gamification effort increases web traffic 100\%, employee collaboration 57\%," Case Study in Online Article, May 2012, marketing Sherpa.

[55] V. Vroom, Work and motivation. New York: Wiley, 1964.

[56] K. Salen and E. Zimmerman, Rules of Play: Game Design Fundamentals. MIT Press Ltd, 2003. 